\title{
Vehicle Planetary Gearbox Simulation
}

Tomas Gajdosik ${ }^{1}$, Frantisek Brumercik ${ }^{1 *}$, Michal Lukac $^{1}$ and Pawel Drozdziel ${ }^{2}$

${ }^{1}$ University of Zilina, Faculty of Mechanical Engineerings, Univerzitna 1, Zilina, Slovak Republic; Email: tomas.gajdosik@fstroj.uniza.sk; brumercikf@fstroj.uniza.sk,michal.lukac@fstroj.uniza.sk ${ }^{2}$ Lublin University of Technology, Faculty of Mechanical Engineering, Nadbystrzycka 36, 20-618 Lublin, Poland; Email: p.drozdziel@pollub.pl

*Corresponding Author: Frantisek Brumercik

Abstract: This article is about design and calculation of planetary gearbox which can be used in transport applications. The gearbox is designed with respect to the input parameters. The gearbox has two planetary gears. The model of gearbox is created in Simscape Driveline software containing blocks which represent the key components of the gearbox. There is also a kinematic analysis performed and confronted with the simulation results.

Keywords: vehicle, planetary gearbox, model, simulation

\section{Introduction}

Planetary (epicyclic) gearing is a gear system consisting of one or more outer gears (planet gears) revolving about a central sun gear. Typically, the planet gears are mounted on a movable arm (carrier) and rotate relative to the sun gear [1,2]. Epicyclic gearing systems also incorporate the use of an ring gear with inner toothing, which meshes with the planet gears. The axes of all gears are usually parallel, but for special cases like vehicle differentials, they can be placed at an angle, using bevel gears [3]. The sun gear, carrier and ring gear axes are usually coaxial. Advantages of this type of gears are smaller size as a simple gear, easier power shifting and symmetric distribution of loading $[4,5]$.

\section{Gear Stage Kinematics}

Planetary gears (or epicyclic gears) are typically classified as simple or compound planetary gears. Simple planetary gears have one sun gear, carrier and ring gear and one planet set (Fig. 1). 


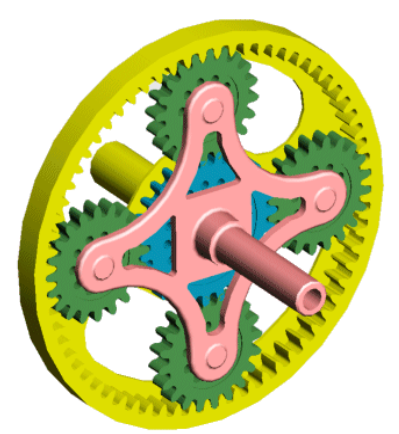

Fig. 1 Simple planetary gear set model. Source: [5]

Compound planetary gears involve one or more of the following three types of structures: meshed-planet (there are at least two more planets in mesh with each other in each planet train), stepped-planet (there exists a shaft connection between two planets in each planet train), and multistage structures (the system contains two or more planet sets) [6]. Compared to simple planetary gears, compound planetary gears have the advantages of larger reduction ratio, higher torque-toweight ratio, and more flexible configurations $[7,8]$.

\section{Two-stage Planet Gear Description}

The solved gearbox consists of two planet stages connected according the desired kinematic structure (Fig. 2).

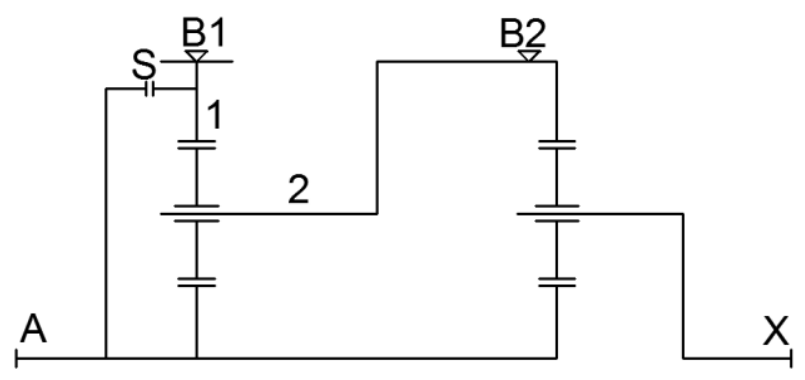

Fig. 2 Solved two-stage planetary gearbox structure. Source: authors

The planetary stage connected to the input A has three basic elements:

$\mathrm{A}$ is the sun gear,

1 is the ring gear,

2 is the carrier.

The planetary stage connected to the output $\mathrm{X}$ has three basic elements:

$\mathrm{A}$ is the sun gear,

$\mathrm{X}$ is the carrier,

2 is the ring gear.

The brakes $\mathrm{B} 1, \mathrm{~B} 2$ activate the 1-st $\left(i_{\mathrm{AX} 1}=2,25\right)$ and 2-nd $\left(i_{\mathrm{AX} 2}=3,5\right)$ gear ratio, the clutch $\mathrm{s}$ activates the 3 -rd gear ratio $\left(i_{\mathrm{AX} 3}=1\right)$. 
Internal gear ratios for this structure are defined as $u_{\mathrm{v} 1}=-3,461$ and $u_{\mathrm{v} 2}=-2,5$.

The input performance is defined as $P_{\mathrm{A}}=67 \mathrm{~kW}$ and the input speed is $n_{\mathrm{A}}=1250 \mathrm{~min}^{-1}$.

\section{Power Flow and Kinematic Analysis}

The power flow through the gearbox at the various gear steps activated is shown in Fig. 3.

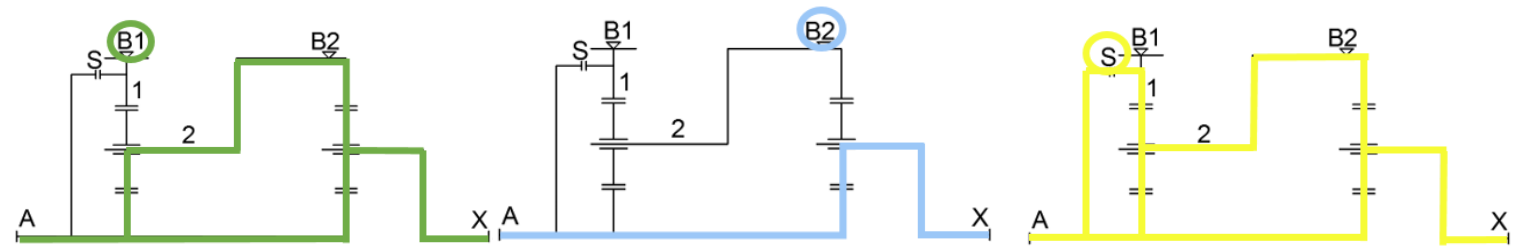

Fig. 3 Gearbox power flow at activated control elements B1, B2 and S. Source: authors

The 1-st gear step is activated by the brake B1. The ring gear of the input planetary gear is stopped and the power flow is divided to both stages of the compound planetary gear.

The 2-nd gear step is activated by the brake B2. The ring gear of the output planetary gear is stopped and the power flows just through the second stage of the compound planetary gear.

The 3-rd gear step is activated by the clutch $\mathrm{S}$, that connects the input shaft $\mathrm{A}$ and the ring gear in the 1-st stage of the compound planetary gear train. The power flows through every element of the compound planetary gear, which rotates at the same speed as the input shaft A.

The kinematic analysis results of the described two-stage planetary gear are presented in table 1.

Table 1 Relative and absolute speeds of the gearbox elements. Source: authors

\begin{tabular}{|c|c|c|c|c|c|}
\hline Element & & $\begin{array}{c}\text { A } \\
\begin{array}{c}\text { (Sun gear of input } \\
\text { gear) }\end{array}\end{array}$ & $\begin{array}{c}\mathbf{X} \\
\begin{array}{c}\text { (Carrier of output } \\
\text { gear) }\end{array}\end{array}$ & $\begin{array}{c}1 \\
\text { (Ring gear of input } \\
\text { gear) }\end{array}$ & $\begin{array}{c}2 \\
\text { (Carrier of input } \\
\text { gear) }\end{array}$ \\
\hline Mode & Mechanism & $\omega_{A}$ & $\omega_{\mathbf{X}}$ & $\omega_{1}$ & $\omega_{2}$ \\
\hline I (B1) & \multirow{11}{*}{ A21/AX2 } & 1 & 0,445 & 0 & 0,224 \\
\hline II (B2) & & 1 & 0,285 & $-0,288$ & 0 \\
\hline III (S) & & 1 & 1 & 1 & 1 \\
\hline Mode & & $\begin{array}{c}\omega_{\mathrm{A}} \\
{[\mathrm{rad} / \mathrm{s}]}\end{array}$ & $\begin{array}{c}\omega_{\mathrm{X}} \\
{[\mathrm{rad} / \mathrm{s}]}\end{array}$ & $\begin{array}{c}\omega_{1} \\
{[\mathrm{rad} / \mathrm{s}]}\end{array}$ & $\begin{array}{c}\omega_{2} \\
{[\mathrm{rad} / \mathrm{s}]}\end{array}$ \\
\hline I (B1) & & 130,899 & 58,250 & 0 & 29,321 \\
\hline II (B2) & & 130,899 & 37,306 & $-37,698$ & 0 \\
\hline III (S) & & 130,899 & 130,899 & 130,899 & 130.899 \\
\hline Mode & & $\begin{array}{c}\mathrm{n}_{\mathrm{A}} \\
{\left[\mathrm{s}^{-1}\right]}\end{array}$ & $\begin{array}{c}\mathrm{n}_{\mathrm{X}} \\
{\left[\mathrm{s}^{-1}\right]}\end{array}$ & $\begin{array}{c}\mathrm{n}_{1} \\
{\left[\mathrm{~s}^{-1}\right]}\end{array}$ & $\begin{array}{c}\mathrm{n}_{2} \\
{\left[\mathrm{~s}^{-1}\right]} \\
\end{array}$ \\
\hline I (B1) & & 20,833 & 9,271 & 0 & 4,666 \\
\hline II (B2) & & 20,833 & 5,937 & -6 & 0 \\
\hline III (S) & & 20,833 & 20,833 & 20,833 & 20,833 \\
\hline
\end{tabular}




\section{Simulation Model Structure and Properties}

The basic elements of the Mathworks Simcape Driveline software model are blocks of one-stage epicyclic gear train with 3 basic elements: sun gear, ring gear and carrier [9]. Fig. 4 shows the mask of the planetary gear block in Matlab/SimScape Driveline software.

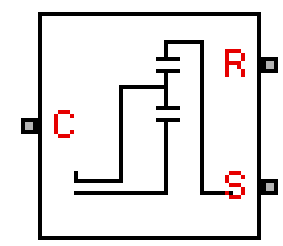

Fig. 4 Planetary gear block. Source: [5]

The planetary gear block has three connection ports:

- C-Carrier,

- $\mathrm{S}-$ Sun gear,

- $\quad \mathrm{R}$ - Ring gear.

This block allows to define the fundamental gear ratio of the planetary gear-stage, e.g. by the number of gear teeth of the sun gear and ring gear put to the block parameters interface. Torque and angular velocity can be calculated by this block either with or without losses in gear mesh with the possibility to take into account the impact of the temperature and also the viscous losses from bearing of the sun and planet gears [10].

The solved gearbox is created by two planetary gear blocks. Each of this planetary gear block has defined its own internal gear ratio. The disk friction clutch block is used modeling brakes (B1, B2) and the clutch (S). These blocks are set by the kinematic structure shown in Fig. 5.

The simulation used solver is ode15s. This is one of many solvers, which we can use for calculation in Simulink environment. It computes the model's state at the next time step using variable-order numerical differentiation formulas (NDFs). These are related to, but more efficient than the backward differentiation formulas (BDFs), also known as Gear's method $[11,12]$.

The different modes $(\mathrm{B} 1=\mathrm{I}, \mathrm{B} 2=\mathrm{II}, \mathrm{S}=\mathrm{III})$ are triggered by Signal builder block. Simulation time is set to 10 seconds. The control signal time schedule is shown in Fig. 6.

The responses of the kinematic parameters of the gearbox to the control signal are presented in Fig. 7. 


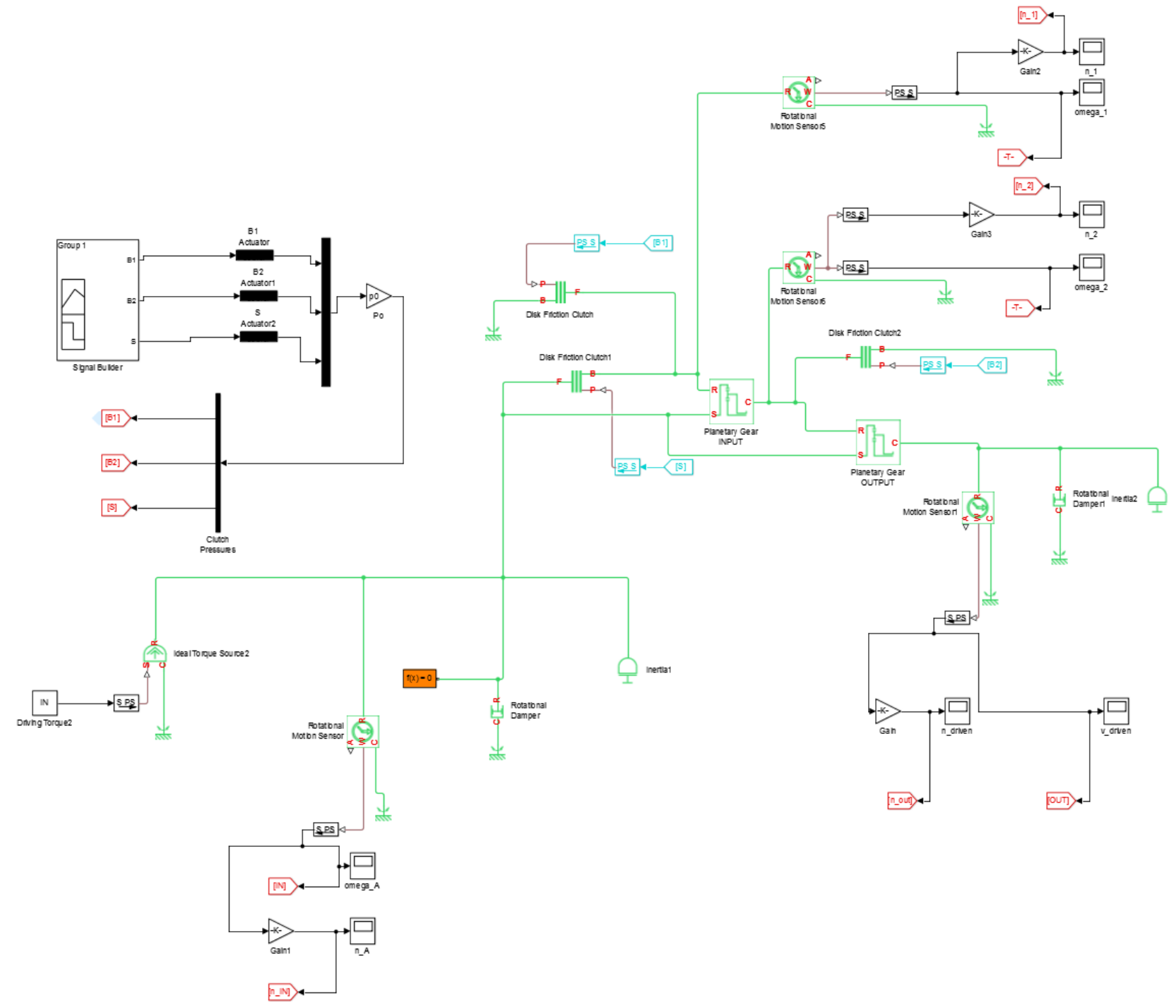

Fig. 5 Gearbox model structure. Source: authors
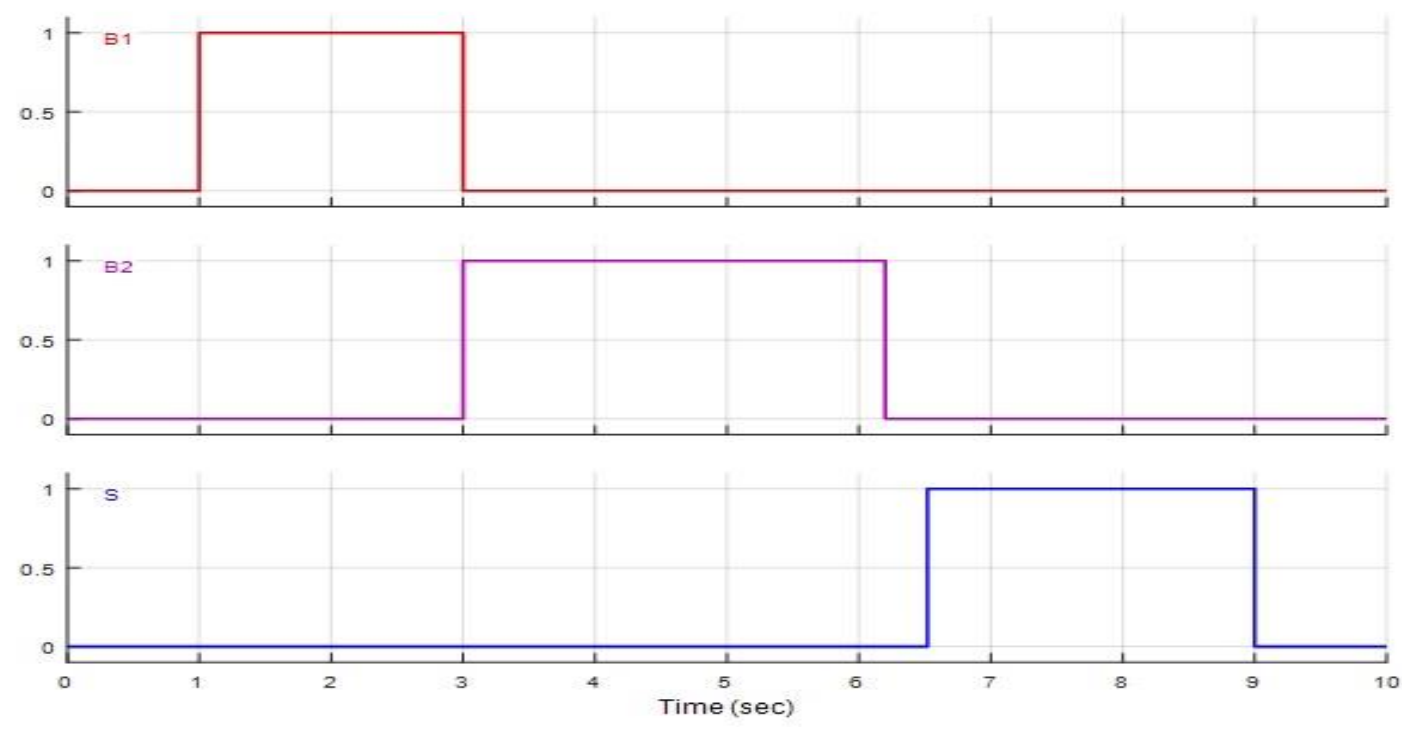

Fig. 6 Control signal time schedule. Source: authors 

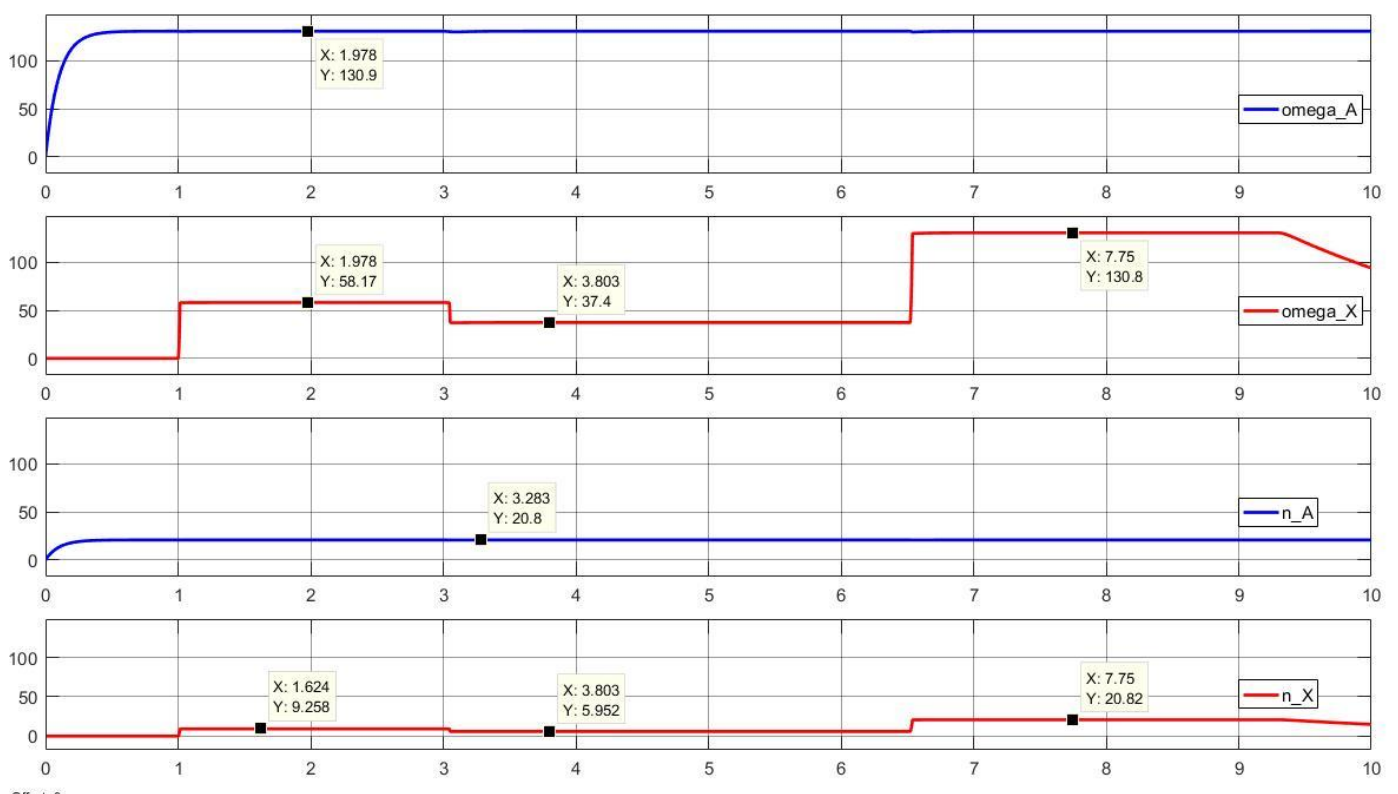

Fig. 7 Gearbox input (A) and output (X) speed responses. Source: authors

\section{Conclusion}

The presented paper describes the possibility of the planetary gearbox structure modeling and its analysis in a simulation environment. The gearbox, which can be used in vehicles and transport applications, is modeled by editable blocks which are connected by physical signals. The responses of the input (A) and output (X) gearbox shaft speed to the control signal activating the operative gearbox elements (brakes B1, B2 and the clutch S) correspond to the kinematic values obtained by the kinematic analysis.

\section{Acknowledgments}

The research is supported by the Cultural and Educational Grant Agency of the Ministry of Education, Science, Research and Sport of the Slovak Republic under the project No. 046ŽU$4 / 2018$.

\section{References}

[1] Kohar, R. \& Hrcek, S. (2014). Dynamic analysis of a rolling bearing cage with respect to the elastic properties of the cage for the axial and radial load cases. Communications, 16(3A), 7481. ISSN 1335-4205.

[2] Hrcek, S., Kohar, R. \& Medvecky, S. (2012). Determination on the maximum roller bearing load with regards to durability thereof using FEM analysis. Communications, 14(3), 55-61. ISSN 1335-4205. 
[3] Drozdziel, P., Brumercikova, E. \& Bukova, B. (2015). The Use of Progressive Methods of Serving Passengers. Transport problems, 10(4). ISSN 1896-0596.

[4] Nieoczym, A. (2005). Application of a transportation flux for determining qualitative indices. Communications, 7(1), 47-48. ISSN 1335-4205.

[5] Kucera, L., Lukac, M., Jurak, L. \& Brumercik, F. (2009). Hydromechanical Automatic Transmission. Communications, 11(2), 33-35. ISSN 1335-4205.

[6] Drozdziel, P. \& Krzywonos, L. (2009). The Estimation of the Reliability of the First Daily Diesel Engine Start-up During its Operation in the Vehicle. Eksploatacja i Niezawodnosc Maintenance and Reliability, 41(1), 4-10. ISSN 1507-2711.

[7] Jedlinski, L., Caban, J., Krzywonos, L., Wierzbicki, S. \& Brumercik, F. (2015). Application of vibration signal in the diagnosis of IC engine valve clearance. Journal of Vibroengineering, 17(1), 175-187. ISSN 1392-8716.

[8] Lukac, M., Brumercik, F., Krzywonos, L. \& Drozdziel, P. (2014). Tension mechanism dynamic analysis. Communications, 16(3A), 184-188. ISSN 1335-4205.

[9] Filo, M. \& Lukac, M. (2005). Modeling and Simulation of Mechanisms with Computer Support, Žilina: EDIS- publisher of University of Žilina, 216 p. ISBN 80-8070-466-X.

[10] Caban, J., Drozdziel, P., Vrabel, J., Sarkan, B., Marczuk, A., Krzywonos, L. \& Rybicka, I. (2016). The research on ageing of glycol-based brake fluids of vehicles in operation. Advances in Science and Technology, 10(32), 9-16.

[11] Caban, J., Marczuk, A., Sarkan, B. \& Vrabel, J. (2015). Studies on operational wear of glycolbased brake fluid. Przemysł Chemiczny, 94(10), 1802-1806.

[12] Faturik, L., Trsko, L., Hrcek, S. \& Bokuvka, O. (2014). Comparison of structural design in high and ultra-high cycle fatigue regions. Transactions of FAMENA, 38(4), 1-12. 